\title{
INFLUENCE OF ANNEALING TEMPERATURE ON THE CRYSTALLIZATION KINETICS OF Fe82Si8B10 AMORPHOUS RIBBON
}

\author{
A. Said Sikder, S. D. Nath* and S. S. Sikder \\ Department of Physics, Khulna University of Engineering \& Technology, Khulna-9203, Bangladesh \\ Received: 31 October 2019 \\ Accepted: 29 May 2020
}

\begin{abstract}
Amorphous soft magnetic materials have significant potential applications in specialist power transformers and in inductive devices. With the composition of $\mathrm{Fe}_{82} \mathrm{Si}_{8} \mathrm{~B}_{10}, 82 \%$ of the transition metals $\mathrm{Fe}$ and about $18 \%$ of metalloid or glass-former elements like B and Si are strongly magnetic at room temperature and offer dynamic opportunities for engineering applications. The crystallization kinetics has been studied by differential thermal analysis (DTA). The sample was annealed in a controlled way in the temperature range of $350-450^{\circ} \mathrm{C}$ at constant annealing time one hour. The kinetics of primary crystallization $\alpha-F e(S i)$ phase and secondary crystallization $\mathrm{Fe}_{2} \mathrm{~B}$ phase was studied as affected due totemperature. The sample annealed at $350^{\circ} \mathrm{C}$ temperature is almost unchanged which is still lower than that of primary crystallization temperature but the same condition when sample annealed at $450^{\circ} \mathrm{C}$ completely shows that the primary crystallization $\alpha-\mathrm{Fe}(\mathrm{Si})$ phase has vanished and crystallization event took place to a good extent.
\end{abstract}

Keywords: Activation energy; Amorphous Ribbon; Annealing; Crystallization kinetics; DTA.

\section{INTRODUCTION}

In recent decades, the effect of composition on the stability and magnetic properties of amorphous ribbon is of enormous interest both for application and magnetic devices. Research may originate from the improvements performed on the change of composition affects at ring ordering through nucleation and growth of crystallites. Recently, Fe-, Co- and Ni- based metallic glasses have received a great deal of attention owing to an attractive combination of electric and magnetic properties. Fe-, Co- and Ni- with metalloid such as $\mathrm{B}, \mathrm{Si}$, or $\mathrm{C}$ produce amorphous alloys with excellent soft magnetic properties (Luborsky, 1980; Petrakovski, 1981; Babilas et al., 2011). The class of alloys containing about $80 \%$ of the transition metals, Fe, Co, and $\mathrm{Ni}$, and about $20 \%$ of metalloid or glass-former elements such as B, C, P, and Si, are strongly magnetic at room temperature and offer important opportunities for engineering applications. The magnetic and structural stability have been evaluated at higher temperatures and are found to be adequate for most foreseeable applications (Graham et al., 1978). In magnetic glass, the macroscopic quantities which are the average kinetics of properties in the atomic scale are perturbed by structural disorder (Sikder et al., 1999). Since the formation of an amorphous ribbon depends on the absence on long range order, changes of composition are expected to affectthe important crystallization parameters like glass transition $\left(T_{g}\right)$ and crystallization $\left(T_{x}\right)$ temperature controlled by thermal treatments like DTA measurements. First DTA peak $T_{g}$ peak corresponds to the precipitation of an ordered bec $\alpha-F e(S i)$ solid solution embedded in an amorphous phase and second peak $T_{x}$ corresponds to boride phase $\mathrm{Fe}_{2} \mathrm{~B}$ for effect on the apparent activation energy of crystallization process (Asgar et al., 1999; Rao et al., 2016; Tawhid et al., 2018). The resultant amorphous solid generally has higher energy than the corresponding crystalline phase. The energy barriers to nucleation and growth of crystalline phase are so high compared with the thermal energy that metastable state can be studied for annealing time which is very long compared with period during which experiments are done. Yu et al. (2019) found the activation energy of crystallization, $E=4.16 \mathrm{eV} / \mathrm{K}$ that indicates high thermal stability of the amorphous phase of the alloy. Till now researchers have not yet been able to formulate a stable set of rules for amorphous ribbons about a single property. The aim of this work is to study the crystallization kinetics of amorphous $\mathrm{Fe}_{82} \mathrm{~B}_{10} \mathrm{Si}_{8}$ ribbon on as cast and annealed conditions. Research in the development and application of amorphous ribbon could be profitable, especially at its new phase is only the effect of composition on the stability of amorphous state which is studied by keeping the heating rate constant with annealed affect.

\section{MATERIAL AND METHODS}

Amorphous ribbons with the nominal composition $\mathrm{Fe}_{82} \mathrm{Si}_{8} \mathrm{~B}_{10}$ were prepared by melt-spinning machine of the ribbon form in the amorphous state rapid solidification technique at the center of Materials Science, National University of Hanoi, Vietnam. With high purity of the constituent elements Fe (99.9\%), Si (99.9\%) and B (99.9\%) were obtained from Johnson Matthey (Alfa Aesar, UK). Fe-Si-B ribbon is of special interest of magnetic elements (Fe) having different structure in their crystallite state tailoring the crystalline phase change of annealing effect as well as activation energy. Crystallization phase analysis was carried outby STA7200 (Thermal Analysis System, HITACHI, JAPAN) in the Solid-State Physics Laboratory of the Khulna University 
of Engineering \& Technology, Khulna, Bangladesh. The activation energy for crystallization of glass transition $\alpha-\mathrm{Fe}(\mathrm{Si})$ and secondary crystallization of $\mathrm{Fe}_{2} \mathrm{~B}$ phases has been calculated using Kissinger's equation (Kissinger et al., 1957; Blaine et al., 2012):

$$
E=-k T_{p} \ln \left(\frac{\beta}{T_{p}{ }^{2}}\right)
$$

Where $\beta$ is the heating rate, $\mathrm{T}_{\mathrm{p}}$ is the crystallization peak temperature, $\mathrm{E}$ is the activation energy and $k$ is the Boltzmann's constant $=8.617 \times 10^{-5} \mathrm{eV} / \mathrm{K}$.

\section{RESULTS AND DISCUSSION}

\subsection{DTA and Annealing}

DTA observation of as cast sample from Figure 1 reveals that there are four exothermic peaks. The first peak is theprimary crystallization $\left(\mathrm{T}_{\mathrm{p} 1}\right)[\alpha-F e(S i)]$ peak and the second peak $\left(\mathrm{T}_{\mathrm{p} 2}\right)$ is the Secondary crystallization $\left(\mathrm{Fe}_{2} \mathrm{~B}\right)$ peak. The soft magnetic properties correspond to the primary crystallization phase and secondary crystallization causes magnetic hardening of the amorphous ribbon. Since the structure of the beneficial ferromagnetic amorphous phase is comprised of $\mathrm{Fe}-\mathrm{Si}$, as a result the study of primary and secondary crystallization temperature is important for the amorphous alloys (Mondal et al., 2012). For this reason, another $3^{\text {rd }}$ and $4^{\text {th }}$ crystallization phase peaks which are interfacial B-rich phase like $\mathrm{Fe}_{3} \mathrm{~B}$, higher order etc. corresponds to crystallization being suppressed by a barrier to redistribution on a long-range scale is not consider. From DTA scan of the primary crystallization peak temperature for as cast sample is incrementing in between $474^{\circ} \mathrm{C}$ to $498^{\circ} \mathrm{C}$ with the increment of heating rate from $10^{\circ} \mathrm{C} / \mathrm{min}$ to $60^{\circ} \mathrm{C} / \mathrm{min}$ and for secondary crystallization this incrimination is occurring in between the temperature $539^{\circ} \mathrm{C}$ to $564^{\circ} \mathrm{C}$ with theincrement of heating rate shown in Figure 1. The negligible peak shifting indicates that the sample is thermally active. It is also to be noted that primary glass transition temperature corresponding to structural relaxation i.e., release of stress initially formed by the rapid solidification technique and secondary crystallization peak is corresponding to re-crystallization that is reordering of the atom to for another crystalline phase. The calculative data for determining the activation energy has been presented in the Table 1 and with the Kissinger plot the activation energy has determined shown in Figure 4. The activation for Primary crystallization phase $(\alpha-\mathrm{Fe})$ is $3.76 \mathrm{eV}$ and for secondary crystallization peak is $3.69 \mathrm{eV}$.
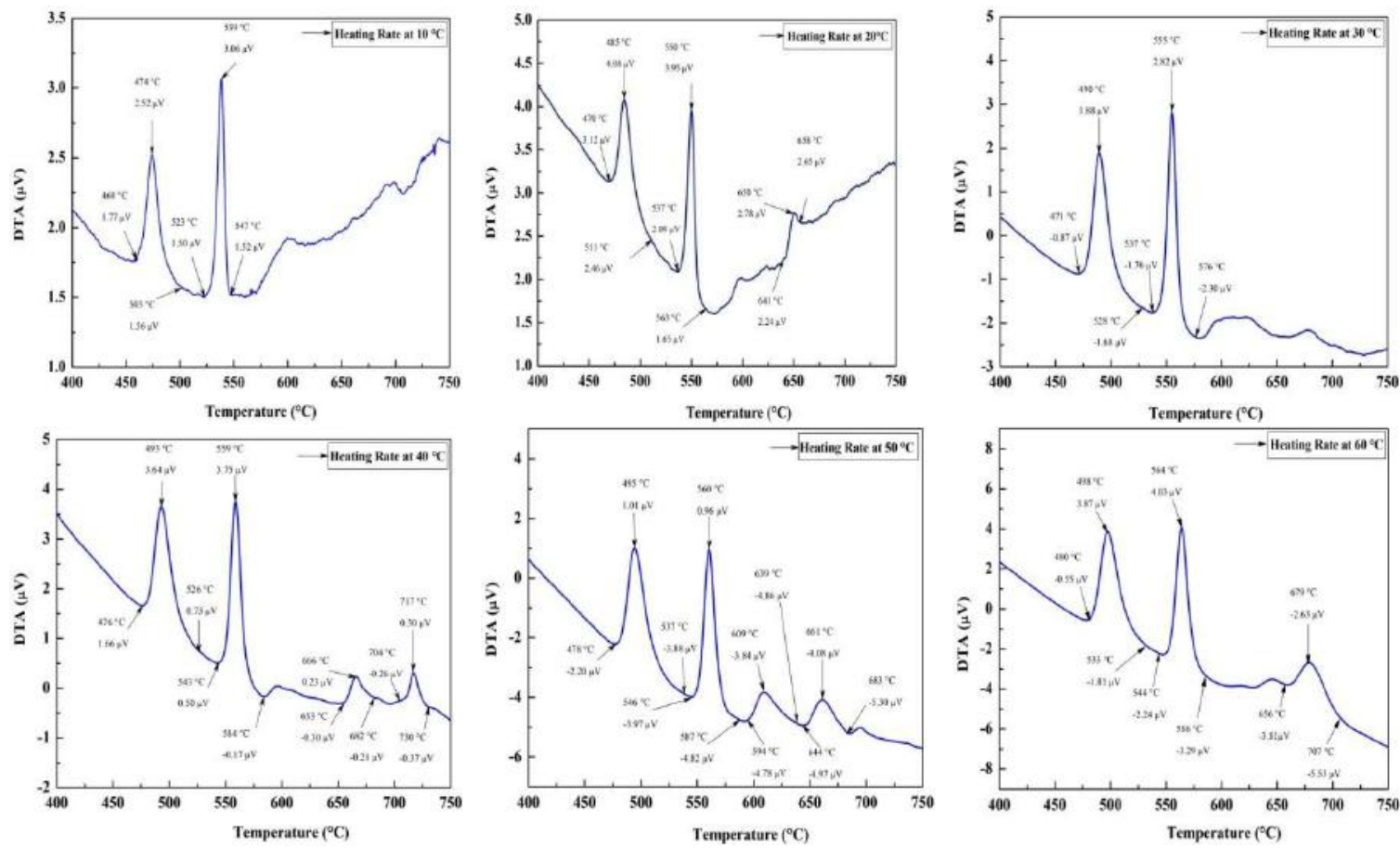

Figure 1: DTA trace of as-cast amorphous ribbon $\mathrm{Fe}_{82} \mathrm{Si}_{8} \mathrm{~B}_{10}$ at heating rate ranges $10^{\circ} \mathrm{C} / \mathrm{min}$ to $60^{\circ} \mathrm{C} / \mathrm{min}$.

The primary crystallization temperature represents the upper limit of use for an amorphous material and the secondary crystallization temperature represents the upper limitof use for nanocrystalline materials (McHenry et al., 1999). In present, the sample was annealed at two steps $\left(350^{\circ} \mathrm{C}\right.$ and $\left.450^{\circ} \mathrm{C}\right)$. To check the crystallization behavior of the sample, it was annealed at $350^{\circ} \mathrm{C}$ and DTA traces were carried out and shown in Figure 2. For 
DTA scan of $350^{\circ} \mathrm{C}$ annealed sample the peak is shifting towards the higher value though the sample holds its amorphousity. The negligible peak shifting indicates the sample is thermally active and it requires more heat energy for the formation of crystalline phases with cumulative heating rate. The peak is shifting for primary phase is in the range between $456^{\circ} \mathrm{C}$ to $526^{\circ} \mathrm{C}$ and for secondary phase this is in between $551^{\circ} \mathrm{C}$ to $591^{\circ} \mathrm{C}$ which is evident from Figure 2. The calculative data for determining activation energy of both the phases presented in Table 2 and with the Kissinger plot the activation energy for primary crystallization phase is $3.58 \mathrm{eV}$ and for secondary crystallization phase this is $3.68 \mathrm{eV}$ was determined and shown in Figure 5. Drop in activation energy is interpreted as at this temperature annealing removes the stress though the sample is still amorphous.
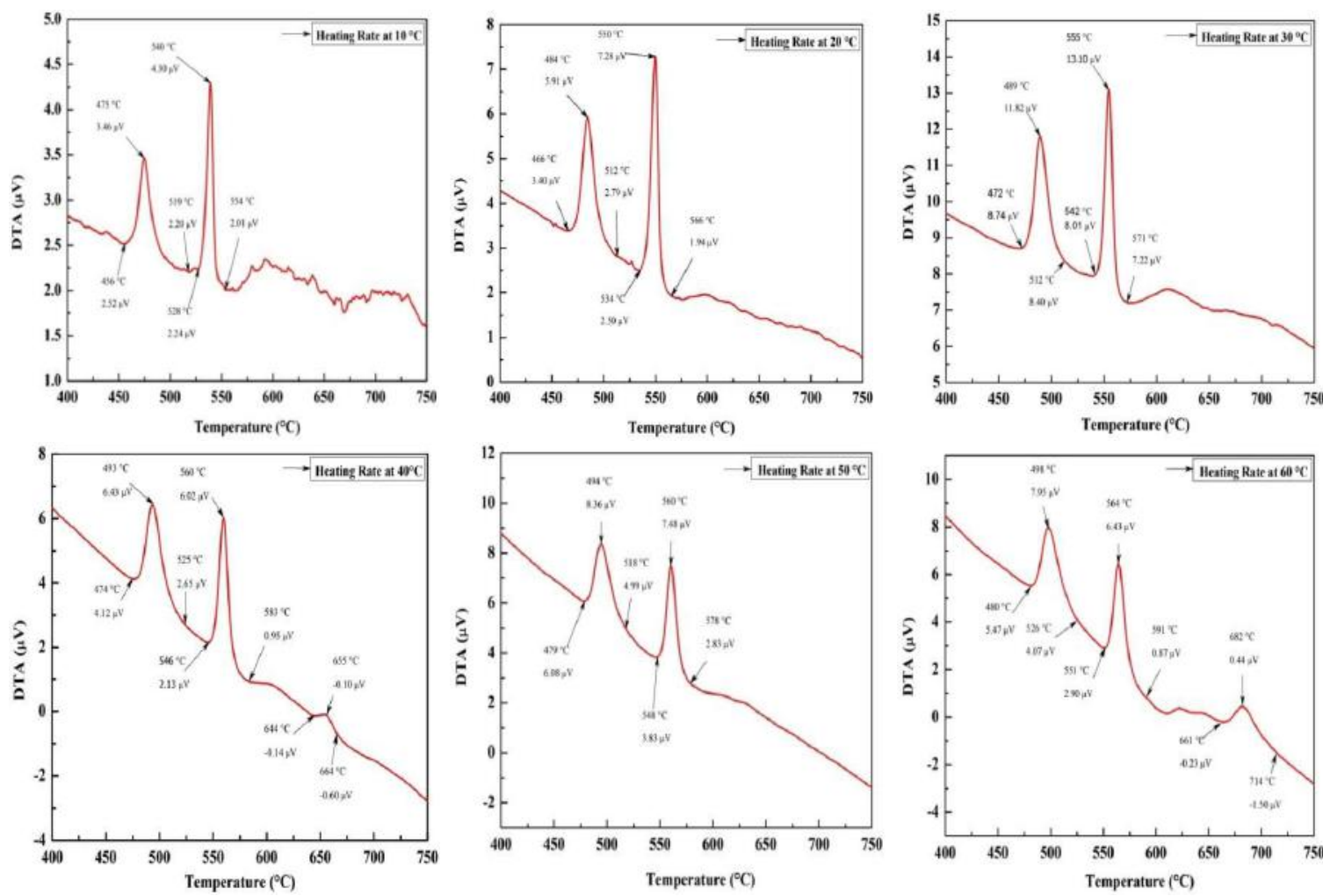

Figure 2: Effects on DTA trace of annealing temperature $350^{\circ} \mathrm{C}$ on the amorphous ribbon $\mathrm{Fe}_{82} \mathrm{Si}_{8} \mathrm{~B}_{10}$ at $10^{\circ} \mathrm{C} / \mathrm{min}$ to $60^{\circ} \mathrm{C} / \mathrm{min}$ at 1 hour.

Table 1: Effect of heating rate on $1^{\text {st }}$ and $2^{\text {nd }}$ crystallization of the as-cast amorphous ribbon with composition $\mathrm{Fe}_{82} \mathrm{Si}_{8} \mathrm{~B}_{10}$ state's calculative data for activation energy

\begin{tabular}{cccccccc}
\hline $\begin{array}{c}\text { Heating rate } \\
\beta^{\circ} \mathrm{C} / \text { min }\end{array}$ & $\begin{array}{c}\text { Heating rate } \\
\beta^{\circ} \mathrm{K} / \text { min }\end{array}$ & $\begin{array}{c}1^{\text {st }} \text { Peak } \\
T_{p_{1}}\end{array}$ & $1 / T_{p_{1}} \times 10^{3}$ & $\ln \left(\frac{\beta}{T_{p_{1}}{ }^{2}}\right)$ & $\begin{array}{c}2^{\text {nd }} \text { Peak } \\
T_{p_{2}}\end{array}$ & $\begin{array}{c}1 / T_{p_{2}} \times \\
10^{3}\end{array}$ & $\ln \left(\frac{\beta}{T_{p_{2}}{ }^{2}}\right)$ \\
\hline 10 & 13.41 & 747.16 & 1.33 & -10.6366 & 812.16 & 1.23 & -10.8034 \\
20 & 26.89 & 758.16 & 1.31 & -9.97003 & 823.16 & 1.21 & -10.1345 \\
30 & 40.24 & 763.16 & 1.31 & -9.58007 & 828.16 & 1.20 & -9.74355 \\
40 & 53.66 & 766.16 & 1.30 & -9.30011 & 832.16 & 1.20 & -9.46538 \\
60 & 80.46 & 771.16 & 1.29 & -8.90803 & 837.16 & 1.19 & -9.07227 \\
\hline
\end{tabular}

As at $350^{\circ} \mathrm{C}$ annealing the sample was still amorphous, an increment of annealing temperature to $450^{\circ} \mathrm{C}$ was experimented through DTA traces. DTA scan was performed to see the annealing effect on its thermal kinetics. At $450^{\circ} \mathrm{C}$ annealed sample DTA traces shows that the primary crystallization peak was vanished, and sample formed crystalline phases. The primary crystallization peak disappear before the crystallization onset temperature and this phenomenon is interpreted as this annealing temperature removes the internal stress which was initially formed by the rapid solidification process also accelerate the nucleation growth rate as a result the onset temperature reduces. The DTA-peak shift can be either positive or negative (as observed in our experiments) depending on the extent of growth of nucleation taking place during the pre-DTA heat treatment or annealing (Gupta et al., 2002). The secondary crystallization peak temperature obtained from Figure 3 is between $540^{\circ} \mathrm{C}$ to $563^{\circ} \mathrm{C}$ with the heating rate of $10^{\circ} \mathrm{C} / \mathrm{min}$ to $60^{\circ} \mathrm{C} / \mathrm{min}$. With Kissinger plot and From Table 3 the activation energy of secondary crystallization peak was determined as $3.31 \mathrm{eV}$ and shown in Figure 6. 

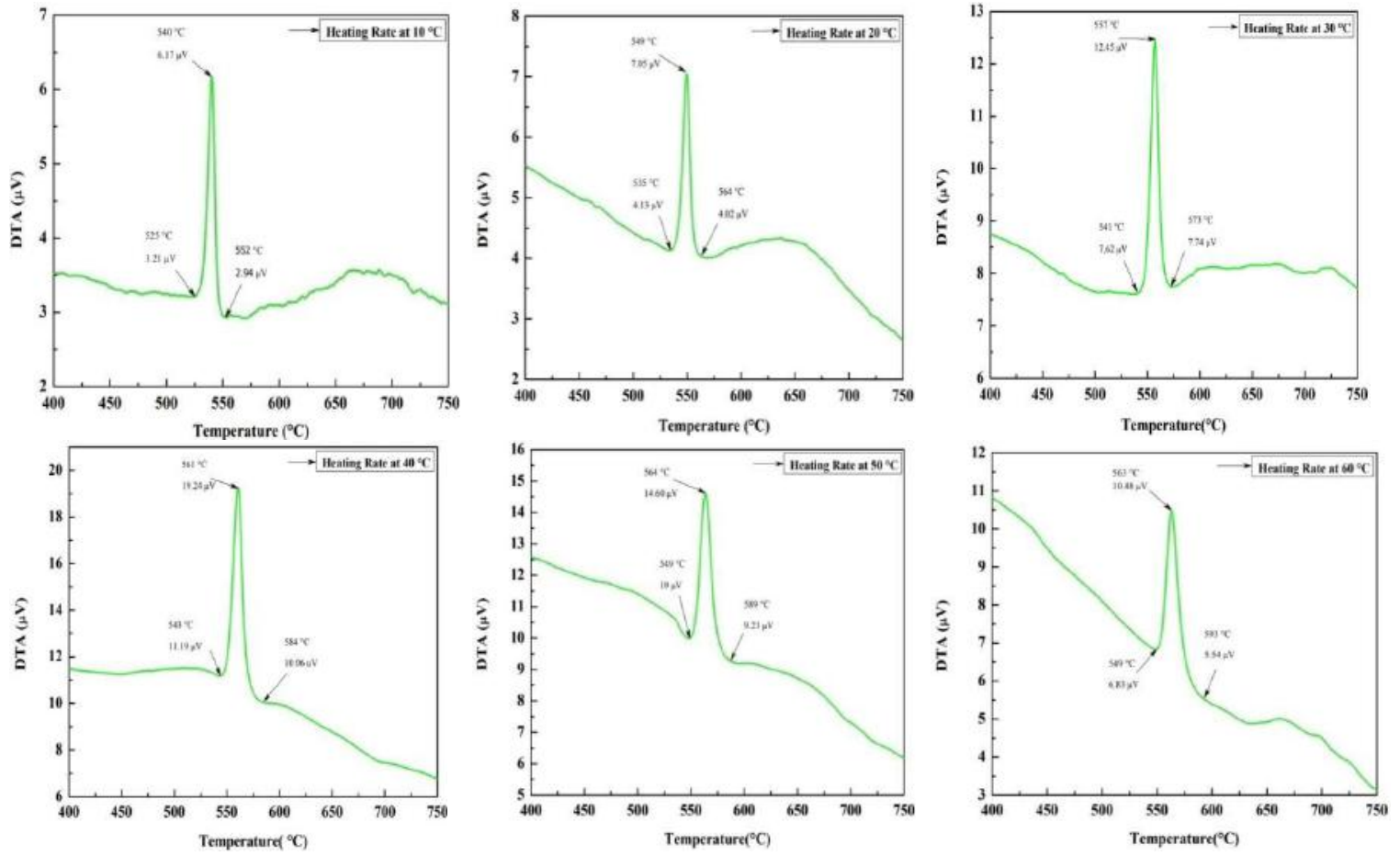

Figure 3: Effects on DTA trace of annealing temperature $450^{\circ} \mathrm{C}$ on the amorphous ribbon $\mathrm{Fe}_{82} \mathrm{Si}_{8} \mathrm{~B}_{10}$ at $10^{\circ} \mathrm{C} / \mathrm{min}$ to $60^{\circ} \mathrm{C} / \mathrm{min}$ at 1 hour

Table 2: Annealing effect of heating rate on $1^{\text {st }}$ and $2^{\text {nd }}$ crystallization of the amorphous ribbon with composition $\mathrm{Fe}_{82} \mathrm{Si}_{8} \mathrm{~B}_{10}$ state's annealed at $350^{\circ} \mathrm{C}$ for constant annealing time one hour

\begin{tabular}{|c|c|c|c|c|c|c|c|}
\hline $\begin{array}{l}\text { Heating rate } \\
\beta^{\circ} \mathrm{C} / \mathrm{min}\end{array}$ & $\begin{array}{l}\text { Heating } \\
\text { rate } \\
\beta^{\circ} \mathrm{K} / \mathrm{min}\end{array}$ & $\begin{array}{c}1^{\text {st }} \\
\text { Peak } \\
T_{p_{1}} \\
\end{array}$ & $1 / T_{p_{1}} \times 10^{3}$ & $\ln \left(\frac{\beta}{{T_{p_{1}}}^{2}}\right)$ & $\begin{array}{c}2^{\text {nd }} \\
\text { Peak } \\
T_{p_{2}}\end{array}$ & $1 / T_{p_{2}} \times 10^{3}$ & $\ln \left(\frac{\beta}{{T_{p_{2}}}^{2}}\right)$ \\
\hline 10 & 13.41 & 748.16 & 1.33 & -10.64 & 813.16 & 1.23 & -10.80 \\
\hline 20 & 26.89 & 757.16 & 1.32 & -9.97 & 823.16 & 1.21 & -10.13 \\
\hline 30 & 40.24 & 762.16 & 1.31 & -9.58 & 828.16 & 1.20 & -9.74 \\
\hline 40 & 53.66 & 766.16 & 1.30 & -9.30 & 833.16 & 1.20 & -9.46 \\
\hline 60 & 80.46 & 771.16 & 1.29 & -8.90 & 837.16 & 1.19 & -9.07 \\
\hline
\end{tabular}
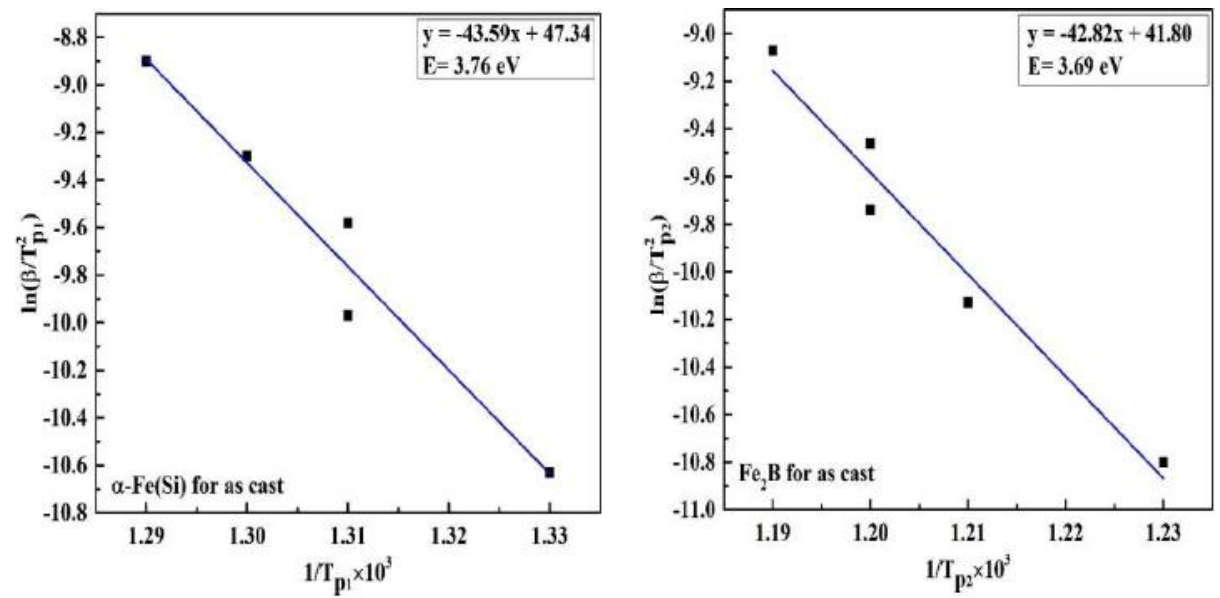

Figure 4: Kissinger's plot to determine the activation of (a) $\alpha-F e(S i)$ phase and (b) $F e_{2} B$ phase for $\mathrm{Fe}_{82} \mathrm{Si}_{8} \mathrm{~B}_{10}$ for as-cast 

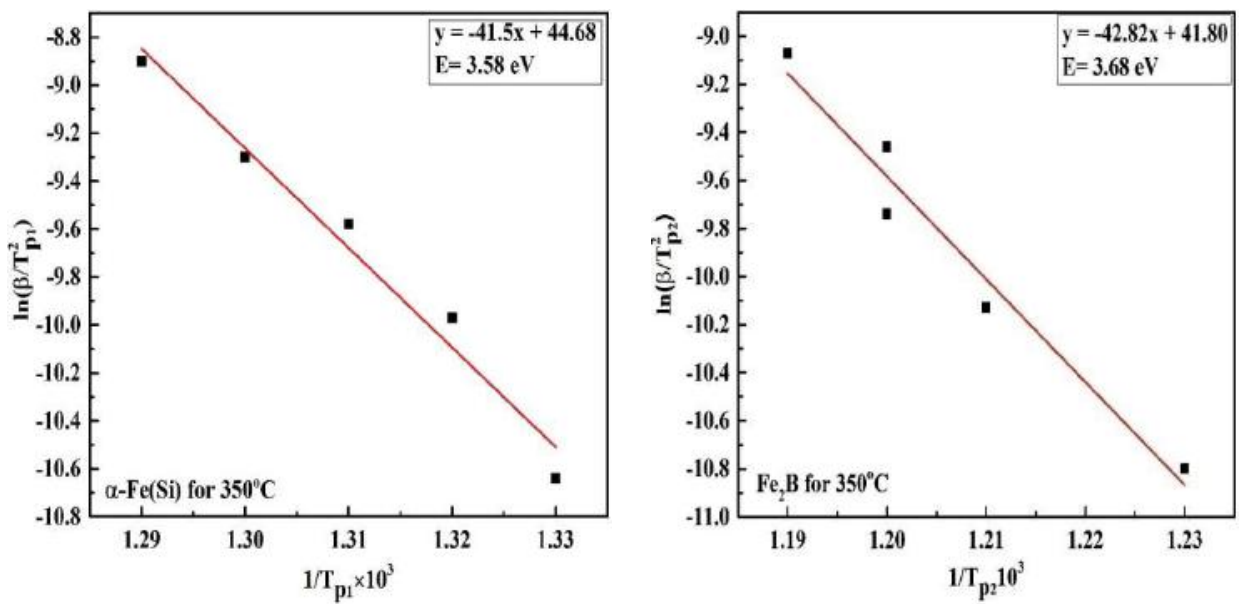

Figure 5: Kissinger's plot to determine the activation of (a) $\alpha-F e(S i)$ phase and (b) $F e_{2} B$ phase for $\mathrm{Fe}_{82} \mathrm{Si}_{8} \mathrm{~B}_{10}$ annealed at $350^{\circ} \mathrm{C}$ for constant annealing time one hour.

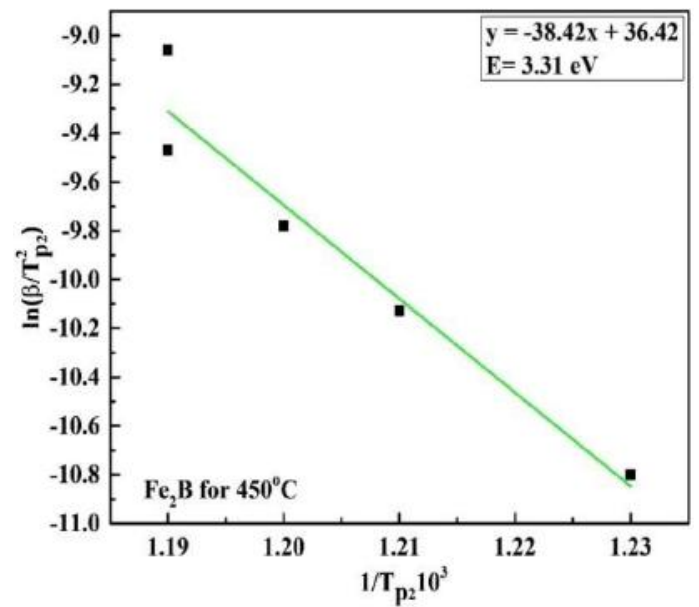

Figure 6: Kissinger's plot to determine the activation of $\mathrm{Fe}_{2} \mathrm{~B}$ phase for $\mathrm{Fe}_{82} \mathrm{Si}_{8} \mathrm{~B}_{10}$ annealed at $450{ }^{\circ} \mathrm{C}$ for constant annealing time one hour

Table 3: Annealing effect of heating rate on $1^{\text {st }}$ and $2^{\text {nd }}$ crystallization of the amorphous ribbon with composition $\mathrm{Fe}_{82} \mathrm{Si}_{8} \mathrm{~B}_{10}$ state's annealed at $450^{\circ} \mathrm{C}$ for constant annealing time one hour

\begin{tabular}{cccccccc}
\hline $\begin{array}{c}\text { Heating rate } \\
\beta^{\circ} \mathrm{C} / \mathrm{min}\end{array}$ & $\begin{array}{c}\text { Heating rate } \\
\beta^{\circ} \mathrm{K} / \mathrm{min}\end{array}$ & $\begin{array}{c}1^{\text {st }} \text { Peak } \\
T_{p_{1}}\end{array}$ & $1 / T_{p_{1}} \times 10^{3}$ & $\ln \left(\frac{\beta}{T_{p_{1}}{ }^{2}}\right)$ & $\begin{array}{c}2^{\text {nd }} \text { Peak } \\
T_{p_{2}}\end{array}$ & $\begin{array}{c}1 / T_{p_{2}} \times \\
10^{3}\end{array}$ & $\ln \left(\frac{\beta}{T_{p_{2}}{ }^{2}}\right)$ \\
\hline 10 & 13.41 & $\ldots$ & $\ldots$ & $\ldots$ & 813.16 & 1.23 & -10.80 \\
20 & 26.89 & $\ldots$ & $\ldots$ & $\ldots$ & 822.16 & 1.21 & -10.13 \\
30 & 40.24 & $\ldots$ & $\ldots$ & $\ldots$ & 830.16 & 1.20 & -9.75 \\
40 & 53.66 & $\ldots$ & $\ldots$ & $\ldots$ & 834.16 & 1.19 & -9.47 \\
50 & 67.07 & $\ldots$ & $\ldots$ & $\ldots$ & 837.16 & 1.19 & -9.25 \\
60 & 80.46 & $\ldots$ & $\ldots$ & $\ldots$ & 836.16 & 1.19 & -9.07 \\
\hline
\end{tabular}

Table 4: The activation energy of $\mathrm{Fe}_{82} \mathrm{Si}_{8} \mathrm{~B}_{10}$ amorphous ribbon before and after annealing

\begin{tabular}{cccccc}
\hline \multicolumn{2}{c}{ Before annealing } & \multicolumn{3}{c}{ After annealing } \\
\hline \multicolumn{2}{c}{ As-cast } & $350^{\circ} \mathrm{C}$ & \multicolumn{2}{c}{$450^{\circ} \mathrm{C}$} \\
\hline$\alpha-\mathrm{Fe}(\mathrm{Si})$ & $\mathrm{Fe}_{2} \mathrm{~B}$ & $\alpha-\mathrm{Fe}(\mathrm{Si})$ & $\mathrm{Fe}_{2} \mathrm{~B}$ & $\alpha-\mathrm{Fe}(\mathrm{Si})$ & $\mathrm{Fe}_{2} \mathrm{~B}$ \\
3.76 & 3.69 & 3.58 & 3.68 & ----- & 3.31 \\
\hline
\end{tabular}

\section{CONCLUSION}

DTA manifest two exothermic peaks for as cast $\mathrm{Fe}_{82} \mathrm{Si}_{8} \mathrm{~B}_{10}$ amorphous ribbon which are corresponds to primary crystallization event temperature $\alpha-F e(S i)$ which indicates stability of amorphous state and magnetic softness. 
The softest magnets corresponds to $\alpha-F e(S i)$ phase to $474^{\circ} \mathrm{C}$ and magnetic hardening $\mathrm{Fe}_{2} \mathrm{~B}$ phase to $531^{\circ} \mathrm{C}$ for this ribbon with heating rate $10^{\circ} \mathrm{C} / \mathrm{min}$. Activation energy of $\alpha-F e(\mathrm{Si})$ phase is $3.76 \mathrm{eV}$ and $\mathrm{Fe}_{2} \mathrm{~B}$ phase is $3.69 \mathrm{eV}$. When the sample was annealed at $350^{\circ} \mathrm{C}$ it holds its amorphousity though reduction in activation energy was found due to removal of internal stress and the sample said to be magnetically soft. Activation energy of $\alpha-$ $\mathrm{Fe}(\mathrm{Si})$ phase is $3.58 \mathrm{eV}$ and $\mathrm{Fe}_{2} \mathrm{~B}$ phase is $3.68 \mathrm{eV}$. The sample annealed at $450^{\circ} \mathrm{C}$ displays diffusive phenomenon and primary crystallization peak vanished which indicates that crystallization took place to a good extent. Activation energy of $\mathrm{Fe}_{2} \mathrm{~B}$ phase is $3.31 \mathrm{eV}$. Heat treatment should be limited by $450^{\circ} \mathrm{C}$ to obtain optimum soft magnetic behavior which corresponds well with the value obtained DTA and in significant influence of annealing effect on the crystallization phase and the activation energy.

\section{REFERENCES}

Asgar, M. A., and Sikder S. S., 1999. Influence of glass forming material on atomic and magnetic ordering of Fe-based metallic glass, Indian Journal of Physics, 73A, 4, 493 - 502.

Babilas,R., Griner S., Sakiewicz P., and Nowosielski R., 2011. Structure, thermal and magnetic properties of $\left(\mathrm{Fe}_{72} \mathrm{~B}_{20} \mathrm{Si}_{4} \mathrm{Nb}_{4}\right)$ 100-xYx $(\mathrm{x}=0.3)$ metallic glasses, Journal of Achievements in Materials and Manufacturing Engineering, 44(2), 140-147.

Blaine, R. L., and Kissinger H. E., 2012. Homer Kissinger and the Kissinger equation, Thermochimica Acta, 540, 1-6.

Graham Jr, C. D., and Egami T., 1978. Magnetic properties of amorphous alloys, Annual Review of Materials Science, 8(1), 423-457.

Gupta, P. K., Baranta G., and Denry I. L., 2003. DTA peak shift studies of primary crystallization in glasses, Journal of non-crystalline solids, 317(3), 254-269.

Kissinger, H. E., 1957. Reaction Kinetics in Differential Thermal Analysis, Analytical Chemistry, 29(11), 17021706.

Luborsky, F. E., 1980. Amorphous Ferromagnetism, Ferromagnetic materials, Edited by F. P. wohlfurth, North Holland Publishing Company, 1, 451.

McHenry, M. E., Willard M. A., and Laughlin D. E., 1999. Amorphous and nanocrystalline materials for applications as soft magnets, Progress in materials Science, 44(4), 291-433.

Mondal, S. P., Maria K. H., Sikder S. S., Choudhury S., Saha D. K., and Hakim M. A., 2012. Influence of Annealing Conditions on Nanocrystalline and Ultra-Soft Magnetic Properties of $\mathrm{Fe}_{73.5} \mathrm{Cu}_{1} \mathrm{Nb}_{3} \mathrm{Si}_{13.5} \mathrm{~B}_{9}$ alloy, J. Mater. Sci. Technol., 28 (1), 21-26.

Petrakovski, G. A., 1981. Amorphous magnetic materials, Institute of Physics, Siberian Branch Academy of Science of the USSR Arasnoyarsky USP Fiz Nank, 134, 305 - 331.

Rao,T. S., Rao T. L. S., and Shaker A. M., 2016. Crystallization Kinetics of Amorphous $\mathrm{Fe}_{77} \mathrm{~B}_{16} \mathrm{Si}_{5} \mathrm{Cr}_{2} \mathrm{Metallic}$ Glass, International Journal of Innovative Research in Science, Engineering and Technology, 5(10), $\mathrm{T} 2$

Sikder,S. S., and Asgar M. A., 1999. The kinetics of atomic and magnetic ordering of Co-based amorphous ribbons as affected by Iron substitution, Thermochimica Acta, 326, $119-126$.

Tawhid M. M., Shil S. K., Shihab M. T., Sikder S. S., and Gafur M. A., 2018. The Crystallization Kinetics, Structural and Magnetic Properties of $\mathrm{Fe}_{72.5} \mathrm{Ag}_{2} \mathrm{Nb}_{3} \mathrm{Si}_{13.5} \mathrm{~B}_{9}$ Nanocrystalline Amorphous Ribbons as affected by Annealing, American Journal of Nano Research and Applications, 6(3), 60-66.

Yu, W., Zhou Q., Liu Z., Haoqun Z., Wang Z., and Hua Z., 2019. Effect of heat treatment on the microstructure and magnetic properties of amorphous alloy $\mathrm{Fe}_{60} \mathrm{Co}_{19} \mathrm{Zr}_{9} \mathrm{~B}_{12}$, Metal Science and Heat Treatment, 6, 26-30. 